\title{
A Preliminary Study on Augmented Reality for Learning Local Wisdom of Indonesian Batik in Vocational Schools
}

\author{
I.Widiaty, L. S. Riza, A. G. Abdullah, Ana \\ Universitas Pendidikan Indonesia \\ Bandung, Indonesia \\ isma@upi.edu
}

\begin{abstract}
On October 2009, UNESCO entitled Indonesian batik as a Masterpiece of Oral and Intangible Heritage of Humanity. There are over 100 variants of batik that are determined by uniqueness on drawing techniques, regions, patterns, colors, customs, etc. Therefore, they commonly represent culture, philosophy, and local wisdom of a place and society where batik was designed. This paper presents a preliminary study on an implementation of Augmented Reality (AR) for explaining and studying culture and local wisdom contained on batik. Basically there are four parts explained as follows: introduction to batik and its philosophy, AR frameworks and its classifications, a short survey of AR for education, and initial design of AR for learning local wisdom on batik. One of benefits using AR for learning media in vocational schools (SMK) is to raise the value of local knowledge batik in an active, interactive, and fun way. Therefore, results from this study are used to improve the media and to suggest reviews directions for future works in this study.
\end{abstract}

\section{INTRODUCTION}

Batik is one of the creative industries that have potential as part of a city branding [1]. Batik industry can also be categorized as highly creative one because it is processed and developed by artistic ideas through a variety of distinctive and original motif [2]. So Batik is able to contribute significantly to the income of the nation, known also as a creative economy [3,4]. Furthermore, Batik is an eco-art industry which puts the concept of environmentally friendly industries [4].

Batik is a typical Indonesian cultural heritage that must be preserved. The award of the UNESCO which sets Indonesian Batik as a Masterpiece of Oral and Intangible Heritage of Humanity in 2009 will be withdrawn if Indonesia can not maintain and preserve this culture. Various efforts can be made to develop and preserve Batik, such as to promote aspects of the culture of batik and the technology used to make Batik [2].

Technological aspects of batik developed systematically targeted and trustworthy is one example of the right way to preserve batik in Indonesia. Currently, research related to technological aspects of batik is more focused on the development of batik design. For example, The Scale Invariant Feature Transform (SIFT) is one of the batik technology that uses a feature extraction method [5]. This SIFT technology is useful for the batik industry to create a geometric pattern becomes more variety and be produced in massive numbers. Another technology that has been developed is Batik Content Based Image Retrieval (CBIR) [6]. CBIR is used to create a data base of batik based feature extraction. It is useful for making indexing and classification of batik. Another example is Batik Fractal, which is one of creative ideas also utilize technology in the manufacture of batik design [7]. Batik Fractal is more popular in the creative community of young people.

In general, the technology explained above has not reached the formal educational institutions, especially in vocational skills program Batik. In fact these institutions make the process of education and learning Batik. Therefore, the Batik technology designed for the younger generation in formal educational institutions are the focus of this study. The young generation is a valuable asset that will be the task of preserving Batik in the future. Furthermore, the introduction of aspects related to contents on the local wisdom of batik will be implemented by Augmented Reality (AR).

In this study, we will introduce to AR, which is a technology that tries to combine real-world objects with virtual ones, so that it brings out and enhances information that may be hidden or not immediately be understood. As a preliminary study, a survey of the AR technologies and their implementations on education that have become state of the art will be described. Initial design of an AR implementation for learning media on local wisdom in Batik will be presented as well.

\section{INDONESIAN BATIK}

\section{A. Short History of Batik}

First, confirm that you have the correct template for your Batik in Indonesia began to be known in the Majapahit period around the late 18th century or early 19th century [8]. At first, it has been known as "Batik Tulis", which refers to Batik made by hand. At that time, Batik is made with pure inspiration by exploring the cultural elements of Indonesia. Ideas on batik design can be an element of flora, fauna, nature, human relationships with other human beings, even the human relationship with God. About in the 1920s, we know another type, which is "Batik Cap" (i.e., Stamped Batik) [8]. This type is a response to consumer demand for batik in a mass production. In this context, Batik began to be industrialized. 
At first, the development of Batik is only in the royal palace of kingdom. Batik has become a symbol of elitist for the royal family at that time. Due to the location of the kingdom is located on the coast, the type of Batik known at that time called rural or coastal Batik [8]. Ornaments coastal Batik is dominated by natural patterns, such as flora, fauna, land, landscapes, and sea. Typical color of coastal Batik is a light one, which is caused partly because of the influence of Chinese and Arabic cultures.

\section{B. Art and Technology on Developing Batik}

In etymology, batik originated from the Java language that comes from the root word "amba", meaning to write and "point" is the point in the real sense. So, Batik is an image that is written on the cloth using the night as well as media batik cloth cover. Dyes used in the process of batik dyes typically use synthetic/ artificial. Synthetic dyes are dyes made with certain chemicals that can be used to dye fabrics.

In general, the following is a way of making Batik:

(i) Creating a pattern/ motif on a piece of paper.

(ii) Moving the pattern/ motif is on the fabric.

(iii) Writing with waxes on the main line of the motif.

(iv) Filling out the motif on the main ornament with lines or dots.

(v) Dyeing technique dab on the desired motif for a given color.

(vi) Coloring with overall dyeing technique of batik cloth.

(vii) Removing waxes with hot water mixed with soda ash.

\section{Philosophies and Customs}

Batik is not only known as an element of artifact (craft), but also contains elements socio-fact (social behavior) and mentifact (idea) [9]. It contains the dimensions of meanings, principles, and goals [10]. It is not only introduced as a piece of cloth without meaning, but be loaded with lofty philosophical components (i.e., the voice of Batik). Integration of these values is what actually should be introduced to the general public, especially the young generation. Philosophical meaning in batik always contains elements of local wisdom, which is typical of Indonesia. Batik teaches the younger generation became more prudent. Therefore, learning Batik is a part of teaching wisdom [11-13]. Therefore, teaching Batik with its philosophy must be a part of the nation's character education, which is based on local wisdom $[1,14,15]$. Other studies also said that teaching wisdom is important to be taught in schools [16-18].

\section{AugMENTED REALITY}

\section{A. Definitions}

In the 1960s, Ivan Sutherland and his students at Harvard University and the University of Utah introduced AR prototypes [19]. Then, in the 1990s, the term "Augmented Reality" was coined by Caudell and Mizell [20] in a study using AR to connect wiring harnesses in Boeing Corporation.

The AR research aims to enhance and manipulate a display of reality by putting and combining it with virtual images, texts, or videos, so that we have new information and perspective. According to the older Virtuality continuum introduced by Milgram as shown in Figure 1, AR is a part of Mixed Reality (MR), which presents real and virtual together within a single frame [21]. It can be seen that at the other side, we can generate Augmented Virtual, which is a new display showing mixed environment between virtual and its augmentations. Do not number text heads-the template will do that for you.

Finally, complete content and organizational editing before formatting. Please take note of the following items when proofreading spelling and grammar:

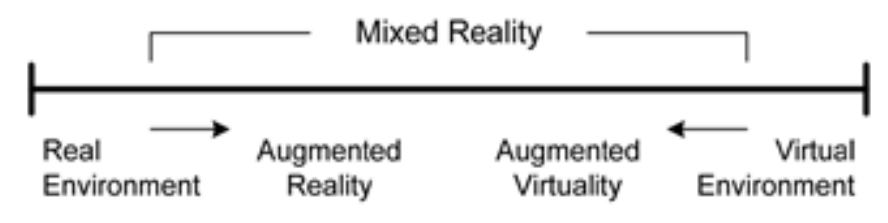

Fig. 1. Milgram's reality-virtuality continuum [21].

Even though AR has been developed since the 1960s and attract a lot attention since the 1990s, there is no official agreement regarding AR's definitions. In the following, we state important definitions introduced by some researchers. In the study [22], an AR system has to fulfill the three requirements:

(i) combine the real and virtual,

(ii) registered in the real world in $3 \mathrm{D}$, (iii) interactive in real time.

Therefore, according to this definition, films that blends virtual objects with a real environment in $3 \mathrm{D}$ are not included in AR because they are not interactive media. Another definition arguing that AR should not restricted was introduced by Kopler [23]. Kopler defines AR as any technologies that mixes real and virtual information so that users get useful experiences. Moreover, from education perspective, AR could be developed by varied hardware, such as head-mounted display, hand-held devices, desktop, laptop, etc [24].

\section{B. A Survey on Augmented Reality Technologies}

Several survey papers have been presented by researchers. In Figure 2, we provide a summary showing a taxonomy of AR based on its technology that is obtained from the literature and also adopted from the studies in [22, 25-27]. It can be seen that we can classify into six categories: Tracking technologies, type of trackers, display devices, interaction modes, software libraries, and applications. In tracking technologies, AR can use sensor, vision, image matching, and hybrid-based methods. Currently, three strategies are used as a tracker, which are marker, marker-less, and Global Positioning Systems (GPS). Marker refers to the implementation of AR based on some specific tags whereas the second is a technique that relies on image recognition on the real object to apply AR. In a way to display AR, we consider some types including in aural, visual, and their positions. According to the interaction, three models can be used, which are tangible AR, collaborative AR, and their hybrid. Nowadays, researchers have been developing several frameworks generating AR, such as ARToolKit, Vuforia, Studierstube, etc. Moreover, the following is a list of AR 
applications in the literature: medical, manufacture, annotation and visualization, education, etc. Furthermore, a short review of AR for education is provided in the next subsection.

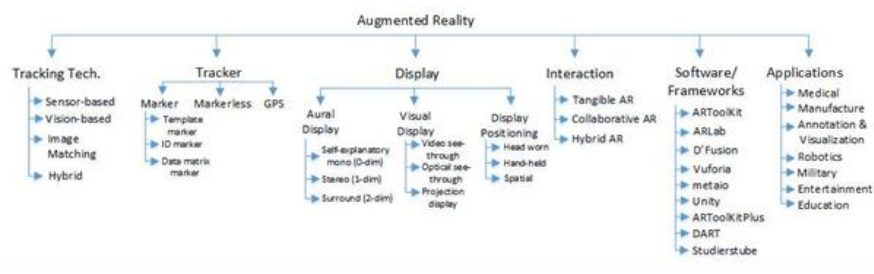

Fig. 2. A taxonomy of augmented reality

\section{Augmented Reality for Educational Purposes}

As shown in Table 1, AR has been widely used in the fields of education, for example mathematics, astronomy, physics, art, engineering, medical, etc. In general speaking, $\mathrm{AR}$ is implemented as a medium of learning, so that learning process can be fun, effective, and efficient. In terms of technology, researchers have explored various platforms. For example, some studies were using markers, makerless, and GPS as a tracker in AR. Software used to generate AR is also varied, such as ARToolKit, Studierstube, Construct3D, etc. Furthermore, the AR display is presented in several ways, including video seethrough, see-through monitor, worn head (Head Mounted Display (HMD)), and hand held/mobile.

According to this survey, we can draw the conclusion that the use of AR for education provides the following benefits:

- The AR technology helps students to get involved and explored real world with more depth understanding because of the additional virtual information in the form of text, voice, and video [28].

- Due to the integration of real-world and digital can be done by the AR technology, instructional materials can be presented in more comprehensive, meaningful, and fun manners.

- It can significantly help students to visualize the learning materials. Thus, AR helps to minimize misunderstanding due to the complexity visualization of the concepts [29].

- It is also very possible to be useful to help students with special needs, where visualization of the objects becomes very important.

- It also offers new and different pedagogical concepts from the traditional one.

\section{Proposed Methodology of the AR Implementation}

In this session, we will discuss about the methodology and phases on implementation of the AR technology for learning media on local wisdom embodied in Batik. In general, these stages can be seen in Figure 3. The first is to obtain knowledge of the AR technology, which is state of the art, by doing a survey. This step has been explained in this paper.

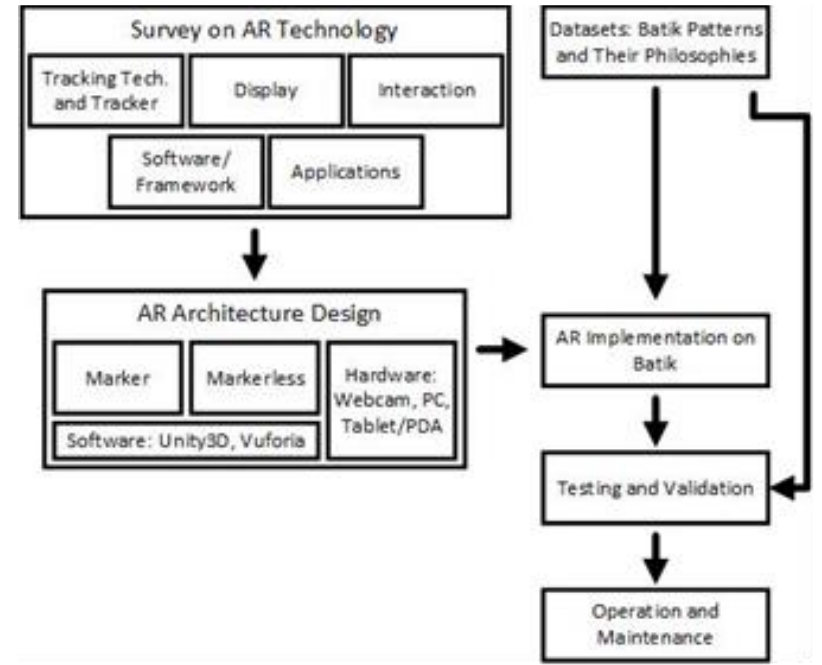

Fig. 3. Steps on the AR implementation for learning batik.

It can be seen that we need to provide datasets containing various batik patterns and their philosophies. In this preliminary research, we focus on Batik Cimahi. Cimahi, located $180 \mathrm{~km}$ south east of Jakarta, takes a place between Bandung and West Bandung Regency. We consider Batik designed originally from Cimahi because it has unique and rich philosophies on its design. There are five main patterns, which are Cireundeu, Ciawitali, Curug Cimahi, Pendidikan Militer (Pusdik), and Kujang. The first is one motif Cimahi more likely to represent the indigenous village located in the area Cireundeu Leuwigajah, South Cimahi. Because the sense of admiration and and the desire to preserve its uniqueness, Cireundeu's cassava was used as a Batik pattern of Cimahi. Ciawitali is the name of a village in the district of Central Cimahi, where at this location there is a lot of overgrown bamboo grove. Therefore, the pattern Ciawitali is inspired by the shape of the bamboo tree. Curug Cimahi is the name of the waterfall located in Cisarua. This pattern describes the beauty of the waterfall and is chosen as an expression of gratitude to God who has endowed natural conditions such beauty to the people of Cimahi. The pattern Pusdik is appointed as one of the basic ideas of Batik Cimahi, because since the Dutch and Japanese colonial period, Cimahi has been known as a place of military education. So, There are some patterns that mimic human and animal forms, e.g., painting various military educational activities (e.g., war games), weapons (e.g., grenades, tanks), Candradimuka, Artillery, and Siliwangi's tigers. Lastly, Kujang is a traditional weapon of West Java. The Kujang pattern was developed as a tribute to the pride of West Java heirloom weapons. The Kujang weapon not only saves the message history, but also is typical and very beautiful. The pattern Kujang has been developed as Batik Cimahi, such as Lereng Kujang, Kujang Cakra, and so forth.

In the part AR architecture design, we are planning to implement two kinds of tracker: marker and markerless. These technologies require sophisticated approaches for image recognition, so that minimum standard of quality, such as information accuracy, image register, distance, etc., can be achieved. Furthermore, at least there are two software libraries used for AR hand-held display (i.e., using PDA/tablet): Unity3D and Vuforia. After preparing the AR architecture, we implement 
it by considering available datasets. Testing and validation are performed to ensure the system before being ready to operate and maintain.

\section{CONCLUSION AND FUTURE WORK}

Four contributions have been presented in this paper, as follows:

(i) an introduction to batik and its philosophies,

(ii) a review on AR frameworks and technologies,

(iii) a short survey of AR for education, and

(iv) an initial design of the AR architecture for learning local wisdom on batik.

In the future, we will attempt to implement AR technology for learning batik as the methodology and architecture explained in this paper. Furthermore, we also need to consider pedagogical aspects when implementing AR for education.

\section{REFERENCES}

[1] Marwati S, Sugihartono R A et al. 2014 Arts and Design Studies 178 18

[2] Ismail T, Wiyantoro L S, Muchlish M et al. 2012 Procedia-Social and Behavioral Sciences 65 33-38 [3] Novani S, Putro U S and Hermawan P 2014 Procedia-Social and Behavioral Sciences 115 324-331

[3] Mayangsari L, Novani S and Hermawan P 2015 Procedia-Social and Behavioral Sciences 169 281-288

[4] Nurhaida I, Noviyanto A, Manurung R and Arymurthy A M 2015 Procedia Computer Science 59 567-576 [6] Rangkuti A H, Rasjid Z E and Santoso D J 2015 Procedia Computer Science 59 577-583

[5] Margried N 2015 Procedia-Social and Behavioral Sciences 184214 222 [8] Borshalina T 2015 Procedia-Social and Behavioral Sciences 169 217-226 [9] Prawira N G 2014 Tawarikh:International Journal for Historical Studies, 6(October), 105-120

[6] Sunarya Y Y and Anas B 2014 Journal of Visual Art and Design 69 16

[7] Sternberg R J, Reznitskaya A and Jarvin L 2007 London Review of Education 5 143-158 [12] Sternberg R J 2001 Educational psychologist 36 227-245

[8] Martin M K and Pison R M d 2005 Religious Education 100 157-173

[9] Patriadi H B, Bakar M Z A and Hamat Z 2015 Procedia Environmental Sciences 28 100-105 [15] Widodo J 2012 Procedia-Social and Behavioral Sciences 42 6-11

[10] Pornpimon C, Wallapha A and Prayuth C 2014 Procedia-Social and Behavioral Sciences 112 626-634

[11] Bredillet C N, Conboy K, Davidson P and Walker D 2013 International Journal of Project Management 31. 1072-1088

[12] Wei X, Weng D, Liu Y and Wang Y 2015 Computers \& Education 81 221-234

[13] Sutherland I E 1968 A head-mounted three dimensional display Proceedings of the December 9-11, 1968, fall joint computer conference, part I (ACM) pp 757-764

[14] Caudell T P and Mizell D W 1992 Augmented reality: An application of heads-up display technology to manual manufacturing processes System Sciences, 1992. Proceedings of the Twenty-Fifth Hawaii International Conference on vol 2 (IEEE) pp 659-669

[15] Milgram $P$ and Kishino F 1994 IEICE TRANSACTIONS on Information and Systems 77 1321-1329 [22] Azuma R T et al. 1997 Presence 6 355-385

[16] Klopfer E 2008 Augmented learning: Research and design of mobile educational games (Mit Press)

[17] Broll W, Lindt I, Herbst I, Ohlenburg J, Braun A K and Wetzel R 2008 IEEE Computer Graphics and Applications 40-48

[18] Zhou F, Duh H B L and Billinghurst M 2008 Trends in augmented reality tracking, interaction and display: A review of ten years of ismar Proceedings of the 7th IEEE/ACM International Symposium on Mixed and Augmented Reality (IEEE Computer Society) pp 193-202

[19] Van Krevelen D and Poelman R 2010 International Journal of Virtual Reality 91 [27] Saidin N F, Halim N D A and Yahaya N 2015 International Education Studies $8 \mathrm{p} 1$

[20] Dunleavy M, Dede C and Mitchell R 2009 Journal of Science Education and Technology 18 7-22

[21] Cerqueira C and Kirner C 2012 Developing educational applications with a non-programming augmented reality authoring tool World Conference on Educational Multimedia, Hypermedia and Telecommunications vol 2012 pp 2816-2825

[22] Kaufmann H and Schmalstieg D 2003 Computers \& Graphics 27339 345

[23] Coffin C, Bostandjiev S, Ford J and Hollerer T 2010 Enhancing classroom and distance learning through augmented reality World Conference on Educational Multimedia, Hypermedia and Telecommunications vol 2010 pp 1140-1147

[24] Fleck S and Simon G 2013 An augmented reality environment for astronomy learning in elementary grades: An exploratory study Proceedings of the 25 i'eme conf'erence francophone on l'Interaction Homme-Machine (ACM) p 14

[25] Yeom S j 2011 Changing Demands, Changing Directions. Proceedings ascilite Hobart 1377-1383 [34] Cuendet S, Bonnard Q, Do-Lenh S and Dillenbourg P 2013 Computers \& Education 68 557-569

[26] [35] Barraza Castillo R I, Cruz Sanchez V G and Vergara Villegas O O 2015 Mathematical Problems in Engineering 2015.

[27] Mart'in-Guti'errez J, Contero M and Alcan iz M 2010 Evaluating the usability of an augmented reality based educational application Intelligent tutoring systems (Springer) pp 296-306

[28] Dünser A, Steinbügl K, Kaufmann H and Glück J 2006 Virtual and augmented reality as spatial ability training tools Proceedings of the 7 th ACM SIGCHI New Zealand chapter's international conference on Computer-human interaction: design centered HCI (ACM) pp 125-132

[29] Mart'in-Guti'errez J, Saor'in J L, Contero M, Alcan iz M, P'erez-Lopez D C and Ortega M 2010 Computers \& Graphics 34 77-91

[30] Maier P, Tonnis M and Klinker G 2009 Dynamics in tangible chemical reactions Proceedings from the

[31] International Conference on Chemical Engineering (ICCE 2009) (Citeseer)

[32] Klopfer E and Squire K 2008 Educational Technology Research and Development 56 203-228 [41] Kerawalla L, Luckin R, Seljeflot S and Woolard A 2006 Virtual Reality 10 163-174

[33] Rosenbaum E, Klopfer E and Perry J 2007 Journal of Science Education and Technology 16 31-45

[34] Enyedy N, Danish J A, Delacruz G and Kumar M 2012 International Journal of Computer-Supported

[35] Collaborative Learning 7 347-378 